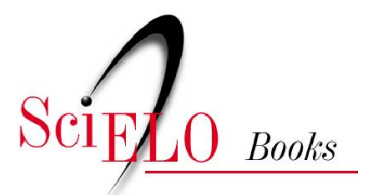

\title{
Inserção internacional, integração e desenvolvimento do Equador na hora da crise mundial e da refundação
}

\author{
Nilson Araújo de Souza
}

\section{SciELO Books / SciELO Livros / SciELO Libros}

SOUZA, NA. Inserção internacional, integração e desenvolvimento do Equador na hora da crise mundial e da refundação. In OLIVEIRA, RP., NOGUEIRA, SG., and MELO, FR., orgs. América Andina: integração regional, segurança e outros olhares [online]. Campina Grande: EDUEPB, 2012. pp. 161-187. ISBN 978-85-7879-185-8. Available from SciELO Books <http://books.scielo.org $>$.

\section{(c) $\frac{1}{\mathrm{BV}}(2)$ (2)}

All the contents of this work, except where otherwise noted, is licensed under a Creative Commons Attribution-Non Commercial-ShareAlike 3.0 Unported.

Todo o conteúdo deste trabalho, exceto quando houver ressalva, é publicado sob a licença Creative Commons Atribuição Uso Não Comercial - Partilha nos Mesmos Termos 3.0 Não adaptada.

Todo el contenido de esta obra, excepto donde se indique lo contrario, está bajo licencia de la licencia Creative Commons Reconocimento-NoComercial-CompartirIgual 3.0 Unported. 


\title{
Inserção internacional, integração e desenvolvimento do Equador na hora da crise mundial e da refundação
}

\author{
Nilson Araújo de Souza
}

\section{Resumo}

O objetivo deste texto é analisar a reação do governo equatoriano ao impacto da crise que, em 2007, ressurgiu nos EUA, inicialmente sob a forma de crise imobiliária. $\mathrm{O}$ Equador havia recém-iniciado um processo de transformação com base no programa "re-fundacional" implementado pelo governo de Rafael Correa. Essa transformação, no entanto, defrontava-se com vários obstáculos, dentre os quais se destacava a dolarização da economia. Esse limite bloqueava a capacidade de o governo praticar políticas monetária, fiscal e cambial. Apesar disso, a economia equatoriana foi uma das que melhor enfrentou a crise. Além de haver provocado no Equador um impacto menor do que o experimentado pela média da América Latina e do mundo, a crise teve uma menor duração naquele país. Postulamos que esse resultado se 
deve ao processo de reconstrução das estruturas estatais que haviam sido desmontadas no período anterior e à utilização dessas estruturas para promover o investimento público, os programas sociais e a dinamização do mercado interno. Além de limitadas pela dolarização, essas mudanças defrontam-se com os limites impostos pelo ainda forte peso do capital estrangeiro no país, pela preponderância do modelo primário-exportador, pela economia rentista baseada no petróleo e pela forte concentração de riqueza e renda..

\section{Abstract}

The purpose of this work is to analyze the response of equatorian government to the impact of a crisis that, in 2007, emerge again at the US, initially as a mortgage crisis. Ecuador had newly begun a transformation process lay on a "re-foundation" program put into practice by Rafael Correa government. However, this transformation faced several obstacles; among them a dollarized economy played a key roll. It restricted government capacity to put both fiscal and monetary policies into practice. Nevertheless, equatorian economy well faced the crisis. The country was hit with strength below Latin America average and the crisis was less long. We assume that it is a result of a state structure rebuilt process and its utilization to promote public investment, social programs and home market increase. Yet, add to dolarization limits, this changes were confined by external capital influence, raw material/export model overweigh, oil rentier economy and concentration of wealth and incomes. 


\section{Introdução}

Este texto é parte de uma pesquisa mais abrangente que está sendo realizada sobre a inserção internacional, a integração e o desenvolvimento de países sul-americanos em processo de transformação caracterizado por seus governantes como "refundação", a saber: Venezuela, Equador e Bolívia. O objetivo deste texto é analisar a reação do governo equatoriano ao impacto da crise que, em 2007, ressurgiu nos EUA, inicialmente sob a forma de crise imobiliária.

O Equador havia recém-iniciado um processo de transformação econômica, social, política e cultural com base no programa implementado pelo governo de Rafael Correa. Essa transformação, no entanto, defrontava-se com vários obstáculos, dentre os quais se destacava a dolarização da economia. Esse limite bloqueava a capacidade de o governo praticar políticas monetária, fiscal e cambial, bem como programas de desenvolvimento. Apesar disso, a economia equatoriana foi uma das que melhor enfrentou a crise ${ }^{1}$.

\section{A derrota do neoliberalismo e a vitória de Rafael Correa}

No início de 2005, depois de crescente oposição e levantes maciços em Quito, as Forças Armadas desconheceram o governo de Lúcio Gutiérrez e o Congresso o destituiu, assumindo, em seu lugar, o vice Alfredo Palácio, em abril daquele ano.

1 Em 2010, segundo o Instituto Nacional de Estadísticas y Censos, a população do Equador era de 14.306.876 (INEC, 04.03.2011), situando- o em 10\% lugar na escala demográfica da América Latina, ao lado da Guatemala (CEPAL, 2008). 
Antes disso, segundo Rafael Correa, Gutiérrez "tratou de consolidar um modelo de desenvolvimento já em crise no resto do mundo, rechaçado nas urnas [o candidato que defendeu esse modelo, Osvaldo Hurtado, teve $1 \%$ dos votos], e que foi um fracasso quanto à eficiência e equidade na América Latina" (CORREA, 2010, p.109).

Em seu curto período, Palácio, ainda que timidamente, iniciou uma reação ao neoliberalismo: "realizou algumas reformas petroleiras que reivindicaram para o Equador o controle de seus recursos naturais. Sua política exterior foi digna e sua postura frente ao conflito colombiano foi firme" (AYALA MORA, 2008, p.124). "Suas realizações incluíam maiores investimentos nas áreas sociais e na reativação da produção petroleira sem capital estrangeiro" (PEDROSO, 2010, p.13).

O novo presidente nomeou como ministro de Economia e Finanças o economista Rafael Correa, que integrava um grupo de economistas progressistas do país. Correa rapidamente ganhou popularidade ao começar a mudar a política econômica. Além de usar as receitas petroleiras para programas sociais, liderou no Congresso a luta vitoriosa pela derrogação de um dos mais espúrios esquemas de renegociação da dívida externa, designado de Fundo de Estabilização, Inversão Social e Produtiva e Redução do Endividamento Público (FEIREP). Com isso, reduziu o peso da dívida externa. Pediu demissão do cargo, apenas três meses depois da posse, devido a desentendimentos com o presidente a propósito de uma negociação de empréstimo com o Banco Mundial. Mas estava no auge de sua popularidade ${ }^{2}$.

2 Em pesquisa de opinião, $60 \%$ da população afirmaram ter confiança nele. 
Criou, a seguir, a Aliança Pátria Altiva e Soberana, conhecida como Aliança PAIS, e lançou-se candidato a presidente da República nas eleições que se realizariam em novembro de 2006. Houve um grande número de candidatos, mas foi para o segundo turno com Correa um dos empresários mais ricos do país, Álvaro Noboa, do Partido Renovador Institucional da Ação Nacional (PRIAN), em sua terceira candidatura presidencial. Noboa apresentou propostas nos marcos de um neoliberalismo extremado, deixando evidente a polarização entre as duas candidaturas. Para Recalde, havia a "certeza de que se teria que eleger entre duas concepções absolutamente distintas sobre a reforma política, o papel do Estado, a função do mercado, as relações internacionais e as políticas públicas, para citar alguns temas" (RECALDE, 2007, p.20).

O ex-ministro da Economia, Rafael Correa, galvanizando o sentimento contra o neoliberalismo que tomara conta do povo equatoriano e prometendo mudanças, ganhou as eleições e assumiu o governo em janeiro de 2007. Segundo Coelho, "o principal motivo do sucesso da campanha de Correa foi o fato de ter concentrado suas forças na proposta da criação de uma Assembleia Constituinte" (COELHO, 2006, p.11). Essa bandeira vinha sendo levantada pelos movimentos indígenas e populares como instrumento para refundar o país. A Confederação das Nacionalidades Indígenas do Equador (Conaie) a hasteara desde 1994.

Contribuiu para sua vitória, certamente, o fato de ser um outsider da política praticada pelos partidos tradicionais, aos quais designava pejorativamente de partidocracia. Depois de dez anos de instabilidade política, em que nenhum Presidente conseguiu concluir seu mandato - todos depostos após se 
afastarem dos compromissos de mudança assumidos em campanha -, havia um cansaço nacional em relação às forças políticas tradicionais. Mas, subjacente a isso, estava o fato de que, depois de sua experiência no Ministério da Economia, Correa condensou o sentimento de mudança acumulado ao longo dos dez anos anteriores. Segundo André Luiz Coelho:

De forma bastante semelhante, esses presidentes foram eleitos com plataformas e alianças de centro-esquerda, prometendo medidas populares e contrárias ao neoliberalismo e, uma vez no poder, realizavam exatamente o oposto, ampliando ainda mais as reformas, realizando novos acordos com organismos internacionais de financiamento e aprofundando ainda mais os ajustes macroeconômicos (COELHO, 2008, apud PEDROSO, 2009, p.13).

\section{A "refundação" do Equador e o impacto da crise mundial}

Uma das primeiras iniciativas de Correa ao assumir a Presidência foi realizar uma consulta popular para a convocação de uma Assembleia Nacional Constituinte, cujo objetivo seria "refundar" o país. O sentimento de mudança era tal que, em referendo popular, $82 \%$ da população votaram a favor de uma Constituinte com plenos poderes (PALACIOS, 2008). Havendo obtido ampla maioria na Constituinte, que se reuniu em Montecristi a partir de 2007, o governo logrou definir a feição da nova Constituição, referendada em consulta popular em 2008. 
A nova Constituição representou uma transformação profunda dos marcos institucionais, político-administrativos e jurídicos do Estado equatoriano. Além dos poderes tradicionais das democracias representativas - Executivo, Legislativo e Judiciário -, a Constituinte criou o Conselho de Estado, o Poder Eleitoral e o Poder de Transparência e Controle Social (ECUADOR, 2008).

O Conselho de Estado é um órgão em que "todos os poderes devem dialogar e se articular, com vistas à cooperação e corresponsabilidade entre eles. Ele é composto por representantes de todas as funçóes e é presidido pelo presidente da República" (PEDROSO, 2009, p.24). O poder de Transparência e Controle Social é um dos indicativos do caráter participativo do projeto da nova democracia equatoriana, à medida que seus órgãos contam com a participação de membros das organizações sociais. O objetivo do Poder Eleitoral independente é garantir maior transparência no processo eleitoral.

Os próprios poderes Executivo, Legislativo e Judiciário sofreram importantes mudanças em relação a seus homólogos das democracias representativas. O Executivo e o Legislativo da democracia equatoriana estão sujeitos à revogabilidade, à chamada revocatória. Isso significa que os titulares de mandatos, à exceção dos membros do Poder Judiciário, estão sob permanente controle dos cidadãos. Podem perder seus mandatos desde que $10 \%$ dos eleitores em nível subnacional e $15 \%$ em nível nacional solicitem a revocatória e esta, em referendo popular, seja aprovada pela maioria absoluta dos votos válidos. 
Além disso, existe a chamada morte cruzada. Desde que, por exemplo, o Legislativo bloqueie o Plano Nacional de Desenvolvimento, elaborado pelo Conselho Nacional de Planejamento, o presidente da República pode dissolvê-lo e, ao mesmo tempo, extinguir o próprio mandato, convocando novas eleições gerais. O Conselho Nacional de Planejamento é outra demonstração da democracia participativa equatoriana, já que integra, além dos distintos níveis de governo, a participação cidadã. O Plano que elabora e envia ao Legislativo tem "caráter vinculante para a política econômica e de investimentos do setor público" (FLORES; CUNHA FILHO; COELHO, 2009, p.9).

O Poder Judiciário tem uma característica particular que se faz presente no próprio nome: Função Judicial e de Justiça Indígena. Ou seja, em nível do Judiciário, reconhece-se a decisão dos constituintes de constituir no Equador um Estado Plurinacional ${ }^{3}$. Isso fica claro no artigo 171 da Constituição, que determina:

As autoridades das comunidades, povos e nacionalidades indígenas exercerão funções jurisdicionais, com base em suas tradições ancestrais e seu direito próprio, dentro de seu âmbito territorial,

3 O Estado Plurinacional é uma novidade na América Latina; foi implantado tanto na Bolívia quanto no Equador, como forma de reconhecer os direitos indígenas, seu idioma e sua cultura. O problema é que essa instituição pode dar margem a intentos de desmembrar a nação equatoriana. Por exemplo, representantes da Conaie, principal entidade indígena, questionam a legitimidade da representação do presidente Rafael Correa como chefe de Estado do conjunto da Nação equatoriana. 
com garantia de participação e decisão das mulheres. As autoridades aplicarão normas e procedimentos próprios para a solução de seus conflitos internos, e que não sejam contrários à Constituição e aos direitos humanos reconhecidos em instrumentos internacionais. (ECUADOR, 2008: art. 171).

Os magistrados, por sua vez, não gozam da perpetuidade prevista na não revogabilidade presente na maioria das democracias representativas. Lá o magistrado tem um mandato de nove anos, renovável a cada três anos.

Essas mudanças institucionais faziam parte do que Correa designou de "Revolução Cidadã" e seriam o caminho para a refundação do Estado equatoriano.

Para implementar a refundação prevista na nova Constituição, o governo de Rafael Correa defrontou-se, desde o início, com os limites impostos pelo desmantelamento do aparelho estatal realizado pelos governos que o precederam, pela dolarização da economia ${ }^{4}$ e pelo impacto da crise mundial. Em 2004, na oposição, ele havia qualificado a dolarização de "barbaridade técnica" (CORREA, 2004), referência que repetiu em seu livro de 2010 (CORREA, 2010), já como presidente da República.

4 Antes de cair, em janeiro de 2000, o presidente Jamil Mahuad Witt deu o salto no escuro e decretou a dolarização da economia, sem qualquer preparação técnica prévia. Depois de 115 anos como moeda nacional do Equador, o sucre deu lugar ao dólar estadunidense como moeda de curso legal. Além de perder a soberania, o Equador perdia a capacidade de fazer políticas cambial e monetária. 
A desorganização das estruturas estatais dificultava a realização dos investimentos públicos previstos no PND, bem como o planejamento de longo prazo. Sem moeda própria, o governo estava limitado em sua tarefa de fazer políticas cambial, monetária e fiscal, dificultando a criação dos instrumentos necessários à implementação do PND. A situação se complicava mais ainda diante do impacto da crise mundial. Como reagir a ela sem as estruturas estatais adequadas e cerceado na possibilidade de praticar políticas cambial, monetária e fiscal?

A crise mundial, deflagrada pela implosão da bolha hipoteco-imobiliária dos EUA em meados de 2007, converteu-se em crise financeira generalizada no segundo semestre de 2008 e em recessão generalizada a partir de 2009. Isso significa que, desde o primeiro ano de seu governo, Rafael Correa esteve às voltas com o impacto da crise no Equador.

O impacto da crise mundial sobre a América Latina pode ser dividido em três momentos:

1) até meados de 2008, exacerbação dos preços das commodities, com pressões inflacionárias, fluxos de capitais e pressões altistas sobre as taxas de câmbio, expansão do crédito interno, sustentação ou aceleração do crescimento; 2) no terceiro trimestre de 2008 , violenta reversão dos preços das commodities, ativos financeiros e reais e queda abrupta da liquidez e do crédito, com queda de receitas de exportação, corte do crédito externo, fortes pressões baixistas sobre o câmbio em vários países, mudança na avaliação de riscos e fuga para a segurança em título do 
Tesouro dos EUA; 3) a partir dos últimos meses de 2008, desaceleração da demanda externa e do crescimento da economia mundial, recessão nos países centrais e desaceleração na Ásia, aprofundamento da aversão ao risco e desaceleração generalizada nas economias latino-americanas (CARVALHO et al, 2010, p.5).

Na primeira etapa, prosseguiu e acelerou-se o aumento do preço do petróleo que, em meados de 2008, atingiu o pico de US\$ 156. Depois de haver atingido o patamar de US\$ 9,20 em 1998, a cotação do produto passou a melhorar gradativamente graças à combinação entre a retomada da iniciativa por parte da OPEP e o crescimento da demanda mundial alavancada pela China. Mas, a partir de 2007, os preços foram catapultados pela demanda especulativa provocada pelos capitais que se evadiram da especulação financeira depois que a crise hipoteco-imobiliária deu seus primeiros sinais.

Nesse primeiro momento, o governo equatoriano decidiu aumentar a participação do Estado na renda petroleira. "Em junho de 2006, o governo de Alfredo Palácio determinou a destinação de 50\% dos excedentes petroleiros para o Estado (...), percentual elevado para 99\% pelo governo de Rafael Correa em outubro de 2007" (CARVALHO et al, 2010, p.10). Isso permitiu o aumento do investimento público: sua participação no PIB cresceu de $4 \%$ para $13 \%$.

5 Antes, eram apenas $20 \%$, cabendo os demais $80 \%$ às companhias petroleiras.

6 Cf. palestra realizada em 19.07.2010, para um grupo de pesquisadores brasileiros, pelo Dr. Pedro Paz, ex-ministro da Economia do governo Correa, de onde saiu para ser responsável pela coordenação de uma nova arquitetura financeira para a região. 
Além disso, montou-se uma nova arquitetura financeira doméstica, com o fortalecimento dos bancos públicos ${ }^{7}$; criaram-se instrumentos para proteger a indústria nacional; adotaram-se medidas com vistas a fortalecer a economia popular, como o uso da renda petroleira para programas sociais: o gasto público social aumentou de $4 \%$ do PIB para $8 \%{ }^{8 ;}$ e realizou-se a auditoria da dívida externa, o que redundou no abatimento do valor da mesma? .

O governo foi recompondo a estrutura estatal que havia sido desmantelada. E, com base nela, começou a implementar seu programa de desenvolvimento. Iniciou a mudança da matriz produtiva, retomando o processo de industrialização ${ }^{10}$, e a melhoria das condições de vida da população; além do aumento dos gastos sociais ${ }^{11}$, aumentou-se o salário real:

7 As instituições financeiras públicas são: Banco Nacional de Fomento, Corporação Financeira Nacional, Banco Equatoriano da Habitação e Banco Equatoriano de Desenvolvimento.

8 Conforme palestra ministrada por Alberto Acosta, no dia 22.07.2010, a um grupo de pesquisadores brasileiros.

9 "Segundo a Comissão para a Auditoria Integral do Crédito Público (CAIC), se as taxas de juros houvessem se mantido em $6 \%$ anuais, como se pactuou originalmente, os pagamentos do governo equatoriano haveriam cancelado toda a dívida em 1995. O que se seguiu pagando daria lugar a um valor a cobrar da banca internacional de 5,4 mil milhões de dólares" (SALTOS; VÁZQUEZ, 2009, p.308). Por outro lado, graças à auditoria, a relação dívida externa/PIB caiu à metade, isto é, da faixa de $25 \%$ para cerca de $12,5 \%$ (fonte: BCE. Disponível em: www.ecuadorencifras.com. Acesso em: 04.03.2011).

10 Apesar disso, o setor industrial ainda "não conseguiu constituir-se num eixo de acumulação que garanta o desenvolvimento nacional” (SALTOS; VÁZQUEZ, 2009, p.238).

11 Entre os programas sociais, destaca-se o Bono de Desenvolvimento Humano, "que em meados de 2009 se situava em 30 USD, com aproximadamente 800 mil receptores diretos" (Ibid., 297). 
de um índice de 180,33 em dezembro de $2007^{12}$, o salário mínimo real médio subiu para 194,80 em dezembro de $2008^{13}$. Caiu, em consequência, ainda que timidamente, o índice de pobreza da população: de $37,60 \%$ em dezembro de 2006 para $35,09 \%$ em dezembro de 2008 (INEC, 03.03.2011) ${ }^{14}$.

Investimentos públicos, coadjuvados pela expansão do mercado interno, haveriam de proporcionar o crescimento da economia. Isso foi possível, em grande medida, devido ao aumento da renda petroleira: em função dos elevados preços que vigoraram até meados de 2008, o valor das exportaçóes do produto aumentou de US\$ 8,3 bilhóes em 2007 para US\$ 11,7 bilhões em $2008^{15}$.

Assim, o PIB equatoriano, que já vinha crescendo no contexto do período de "bonança mundial"16, manteve-se em expansão: 2,5\% em 2007 e 6,5\% em 2008 (BCE, 16.02.2011). Em consequência, caiu a taxa de desemprego: de 9,03\% da

12 Deflacionado pelo Índice de Preços ao Consumidor mensal.

13 Fonte: www.bce.fin.ec.

14 O cálculo de índice de pobreza considera uma renda mínima per capita de US\$ 56,64, em valores de dezembro de 2006, corrigidos anualmente pelo IPC.

15 Fonte: www.bce.fin.ec.

16 "A guinada das condições externas é mais dramática por ter se seguido ao período de mais de cinco anos de bonança externa, em que se combinaram condições favoráveis aos países do Continente, com liquidez abundante, forte aumento da demanda por exportações e altas acentuadas dos preços das principais commodities exportadas" (CARVALHO et al, 2010, p.1). Nesse período - 2002-2007 -, o PIB do Equador cresceu a uma média anual de 5\%. Mas, na verdade, essas "condições favoráveis" estavam forjando a vulnerabilidade externa desses países, que cobraria seu preço a partir da crise mundial iniciada em 2007. 
população economicamente ativa em dezembro de 2006 , caiu para 7,5\% em igual mês de 2007 e $2008^{17}$.

Essas medidas se enquadravam na visão do novo governo, que definira a retomada da industrialização por substituição de importações como caminho para o desenvolvimento e considerava fundamental o aumento do papel do Estado como instrumento desse processo, ao lado de uma inserção internacional soberana ${ }^{18}$.

O presidente Correa deixou isso claro em seu livro de 2010:

Para que estas restriçốes possam ser superadas novamente se requerem estratégias explícitas de desenvolvimento, tais como a integração regional, a priorização de compras públicas para produtores nacionais, adequadas proteções ao comércio exterior, e planificação nacional em geral. Cabe indicar que a qualidade das políticas públicas também pode considerar-se como um bem público (CORREA, 2010, p.181).

E completa: "nesse sentido, o papel do Estado é fundamental, basicamente por sua mencionada eficiência alocativa, e particularmente através da provisão de bens públicos que melhorem a competitividade sistêmica, tal como a infraestrutura econômica" (Ibid. p.181).

17 Fonte: www.bce.fin.ec.

18 Cf. palestra do Dr. Pedro Paz, já citada. 
O governo de Correa elaborou sua própria concepção de desenvolvimento. Para ele, o objetivo do desenvolvimento é o melhoramento contínuo da qualidade de vida; assim, deve ser orientado pelas necessidades e demandas dos cidadãos. Seu Plano Nacional de Desenvolvimento contempla as seguintes estratégias: desenvolvimento interno com inclusão social; relações internacionais soberanas com inserção ativa no mercado mundial; diversificação produtiva com maiores níveis de valor agregado, isto é, com industrialização; integração territorial e desenvolvimento rural com o avanço equilibrado de todas as regióes do país; sustentabilidade do patrimônio natural; Estado com capacidade efetiva de planificação, regulação e gestão; democratização econômica e protagonismo social; garantia de direitos (SALTOS; VÁZQUES, 2009, p.319-320).

\section{Integração regional e moeda regional como instrumentos de soberania e desenvolvimento}

Apesar do forte impulso desenvolvimentista promovido pelo Estado, persistia o engessamento imposto pela dolarização e consequente ausência de moeda própria, o que, como já analisamos, limita a possibilidade de implementar política econômica própria. Esse problema pôde ser contornado enquanto os preços do petróleo e, em consequência, a renda petroleira estavam aumentando, mas tenderia a aparecer de maneira mais contundente com o agravamento do impacto da crise internacional.

Mesmo havendo considerado a dolarização uma "barbaridade técnica” à época da sua decretação, Rafael Correa não 
a extinguiu depois que assumiu a presidência da República. Um dos seus ex-ministros e responsável por coordenar a formulação de uma nova arquitetura financeira regional, Pedro Paz, apresenta as explicações.

Segundo Pedro Paz, pequenos estados nacionais não seriam viáveis. Dado o grau de internacionalização da economia mundial, esses estados não teriam instrumentos para defender-se das ações dos monopólios dos países ricos, dentre elas os ataques especulativos dos capitais financeiros. Assim, os países menores da América Latina só poderiam defender suas economias e viabilizar seu desenvolvimento nos marcos de uma regulação continental, respaldada na integração produtiva. A soberania continental, assim conquistada, seria fundamental para garantir a soberania de cada nação. Nesse sentido, ter-se-ia que criar uma arquitetura financeira regional que implicasse a criação de uma moeda regional e de estruturas financeiras e monetárias regionais ${ }^{19}$.

A integração regional seria, portanto, imprescindível não apenas para garantir a extinção da dolarização e a recriação de moeda própria, mas para a própria sobrevivência do Equador enquanto nação. Essa é também a opinião de outro ex-ministro de Correa, Alberto Acosta. Para ele, "através da integração, criar a soberania regional para fortalecer soberanias nacionais" ${ }^{\prime 20}$. O próprio Correa tem essa opinião, ao apresentar a integração regional como a primeira dentre as estratégias de desenvolvimento (CORREA, 2010, p.181).

19 Cf. palestra já citada.

20 Cf. palestra realizada, no dia 22.07.2010, para um grupo de pesquisadores brasileiros. 
Foi por essa razão que, por ocasião da XVIII Cúpula Iberoamericana, em outubro de 2008, o Equador propôs a "criação de uma 'moeda eletrônica', cujo valor dependeria da cotação de várias moedas nacionais da região” (CARVALHO, 2010, p.11). Percebe-se, assim, que a estratégia de Correa para sair da dolarização passa pela integração regional e pela criação de uma moeda regional ${ }^{21}$. Correa sistematizou essa proposta em seu livro de 2010. Afirma ele:

Um passo fundamental para a otimização na utilização da poupança regional e para fazer a América Latina muito mais eficiente no uso de seus recursos, é a nova arquitetura financeira regional (NAFR). O eixo para esta NAFR se baseia em um novo processo de integração que aponte para a criação de um banco regional de desenvolvimento, de um fundo comum de reservas, de um sistema de pagamentos e do impulso de um sistema monetário comum, que possa começar com a emissão de direitos regionais de giro e uma divisa eletrônica regional (CORREA, 2010, p.182-83).

21 É óbvio que, com uma integração regional solidária e cooperativa, pequenas países, como o Equador, podem fortalecer suas economias, mas isso não significa, necessariamente, que a saída da dolarização e a recriação de moeda própria só poderiam ocorrer nos marcos de uma moeda regional. 


\section{A ação estatal diminuiu os efeitos e a duração da crise no Equador}

Quando o impacto da crise mundial se fez sentir mais fortemente na economia equatoriana, sobretudo a partir de 2008-09 com a queda do preço do petróleo $^{22}$ e a diminuição das compras internacionais ${ }^{23}$, o governo do Equador, de um lado, contava para agir com a retomada da reconstrução das estruturas estatais, mas, de outro, estava engessado pela dolarização e, por conseguinte, limitado em implementar políticas macroeconômicas para enfrentar os efeitos da crise.

Apesar dessa limitação, o governo utilizou os instrumentos de que dispunha para agir. Para garantir os investimentos públicos, recorreu às reservas monetárias acumuladas durante o período de alta do preço do petróleo ${ }^{24}$, realizou uma reforma tributária que viabilizou o aumento da receita pública $^{25}$ e utilizou recursos da Previdência Social. Além

22 O preço do produto, que subira de US\$ 80 em fins de 2007 para US\$ 156 em julho de 2008, baixou para US\$30,18 no primeiro trimestre de 2009 (SALTOS; VÁZQUEZ, 2009, p.65). Além disso, caíram fortemente as remessas de emigrantes, que representam cerca de $10 \%$ da população equatoriana: diminuíram 13,3\% de 2008 para 2009.

23 O valor das exportações de petróleo pelo Equador caiu de US \$ 11,7 bilhões em 2008 para US\$ 7 bilhões em 2009. Em consequência, as exportações totais caíram de US\$18,5 bilhões para US\$ 13,8 bilhões (fonte: www. bce.fin.ec). Estas chegaram a cair 43,8\% no primeiro trimestre de 2009 em relação a igual período de 2008 (SALTOS; VÁZQUES, 2009, p.65).

24 As reservas monetárias, numa economia dolarizada, coincidem com as reservas cambiais. Elas haviam subido de US $\$ 2$ bilhões em dezembro de 2006 para US\$ 6,1 bilhões em dezembro de 2008 (fonte: Banco Central do Equador).

25 Entre janeiro-novembro de 2009 e igual período de 2010, a receita pública subiu $27 \%$ e a despesa, $20 \%$. O aumento da receita se deveu, basicamente, ao incremento do Imposto de Valor Agregado (www.bece.fin.ec). 
disso, solicitou novos créditos em organismos internacionais, particularmente o BID e a Corporação Andina de Fomento, além da China, Venezuela e Irã ${ }^{26}$. Ao mesmo tempo, aumentou as tarifas externas para conter as importações e fortalecer a industrialização por substituição de importações e elevou o imposto sobre saída de divisas, de $0,5 \%$ para $1 \%$. O salário real, por sua vez, seguiu subindo, fortalecendo o mercado interno: o índice do salário mínimo real médio, que fora de 194,80 em dezembro de 2008, subiu para 210,63 em dezembro de 2009 e 216,95 em dezembro de $2010^{27}$.

Não foi possível evitar inteiramente o impacto da crise mundial, mas, além de o impacto haver sido menor do que em outros lugares ${ }^{28}$, desapareceu mais rapidamente ${ }^{29}$. O desemprego, por sua vez, depois de haver permanecido estável durante o pior momento (2009), voltou a cair no ano seguinte: a taxa elevou-se de 7,5\% em dezembro de 2008 para 7,93\% em dezembro de 2009 , para voltar a cair, para 6,11\%, em dezembro de $2010^{30}$. A inflação, que atingira a cifra de $8,83 \%$ no auge dos preços das commodities em 2008, baixou para 4,31\% em 2009 e 3,33\% em 2010 (BCE, 03.03.2011).

As ações anticíclicas do governo durante a crise contribuíram para esse resultado, mas nada disso teria sido possível se Rafael Correa não houvesse começado a reconstruir as

26 Cf. palestra de Acosta já citada.

27 Fonte: www.bce.fin.ec.

28 O PIB cresceu 0,36\% em 2009 (BCE, 16.02.2011), quando os países centrais e boa parte da América Latina amargaram uma forte retração da atividade econômica. O PIB da América Latina caiu 1,9\% naquele ano.

29 A primeira estimativa do Banco Central do Equador é de que o PIB teria crescido 3,75\% em 2010 (BCE, 16.02.2011).

30 Fonte: www.bce.fin.ec. 
estruturas estatais no período anterior. Sem isso, teria sido impossível a ação estatal para viabilizar o investimento e o financiamento públicos, bem como a proteção da produção doméstica. A retomada do aumento do preço do petróleo a partir de 2009 também deu sua contribuição ${ }^{31}$. Mas não foi suficiente para evitar o reaparecimento do déficit comercial em 2009 e $2010^{32}$ : em 2009, porque as exportações caíram mais que as importações e, em 2010, porque as importações cresceram mais que as exportações. Tanto para realizar a política fiscal contracíclica quanto para cobrir os déficits comerciais, o governo recorreu às reservas cambiais ${ }^{33}$.

Fiel à sua posição de que a integração regional é um poderoso instrumento para o desenvolvimento e para a defesa das pequenas economias diante de crises internacionais, o governo acelerou as gestóes para estimular a integração sul-americana e caribenha. É importante registrar que, ao mesmo tempo, impôs a derrota do Tratado de Livre Comércio com os Estados Unidos - um dos símbolos da sua administração, ao lado da Constituinte e da auditoria da dívida.

Assim, por ocasião da VII Cúpula da $\mathrm{ALBA}^{33}$, realizada em Cochabamba, Bolívia, em outubro de 2009, quando esse bloco transformou-se de Alternativa Bolivariana para

31 A cotação do produto, que caíra para US $\$ 26,09$ em dezembro de 2008, subiu para US\$ 67,82 em dezembro de 2009 e US\$ 81,52 em dezembro de 2010 (www.bce.fin.ec). Em fevereiro de 2011, em função do processo especulativo desencadeado pela crise política no mundo árabe, já havia ultrapassado os US\$ 100.

32 US\$331,38 no primeiro ano e US\$1,489 bilhão, no segundo (www.bce. fin.ec).

33 Assim, o montante das reservas caiu de US\$ 6,1 bilhões em 2008 para US\$ 3,3 bilhões em dezembro de 2010 (BCE, 31.12.2010). 
as Américas em Aliança Bolivariana para os Povos de Nossa América, o Equador, que estava fora da ALBA, assinou a Declaração final, aderindo a seus princípios e decisóes (DECLARACIÓN, 2009). Entre essas decisões, encontram-se a criação do Sistema Unitário de Compensação Regional de Pagamentos (SUCRE), como caminho para instituir uma moeda regional ${ }^{34}$, e o estabelecimento de um grupo de trabalho para avaliar diferentes alternativas para a criação de um mecanismo de manejo das reservas internacionais, que teria a denominação de "Fundo de Reservas de ALBA-TCP".

Ademais, Correa aproveitou o período de sua presidência temporária da União das Nações Sul-Americanas - UNASUL ${ }^{35}$, a partir de agosto de 2010, para acelerar o processo de formalização e construção real do bloco. Foi assim que impulsionou a constituição de sua Secretaria Geral, que passou a ser ocupada pelo ex-presidente argentino, Néstor Kirchner $^{36}$. Declarou, no momento de sua posse, que tentaria converter a UNASUL em organização de estados latino-americanos para a qual o MERCOSUL e a Comunidade Andina de Nações deveriam convergir.

Os projetos da UNASUL e da ALBA foram propostos, respectivamente, pelo Brasil e a Venezuela, ambos em oposição à proposta estadunidense de criação da Área de Livre

34 O Equador fez a primeira operação com base no sucre regional, ainda de forma simbólica, com a Venezuela, em julho de 2010. Foram transacionadas 5.430 toneladas de arroz.

35 A UNASUL reúne os 12 países da América da Sul, tanto os integrantes do MERCOSUl e da Comunidade Andina de Nações quanto os que estão fora desses blocos: Chile, Guiana e Suriname.

36 Kirchner faleceria logo depois. 
Comércio das Américas - ALCA e expressando um questionamento ao modelo de integração que vinha sendo implementado na região, o qual privilegiava uma visão "comercialista" de integração, baseada na competição. As novas propostas, ao expressarem o posicionamento das correntes progressistas que assumiram governos em vários países da região, condensaram uma visão de integração mais solidária, fundamentada na cooperação.

Essa nova visão teria, no entanto, que se defrontar com dois obstáculos: a pressão dos EUA para realizar acordos bilaterais de comércio com países da região, após o fracasso da ALCA, e as assimetrias nos níveis de desenvolvimento presentes nesses países.

Nesse meio tempo, Correa havia sido reeleito presidente do Equador. Com a aprovação da nova Constituição, todos os mandatos foram extintos e foram convocadas novas eleições. Estas se realizaram em 2009, exatamente quando eram mais fortes no Equador os efeitos da crise mundial.

O candidato que polarizou com Correa foi o ex-presidente deposto Lúcio Gutiérrez. Este, além de procurar comparar os dois governos, apresentou um programa de corte basicamente neoliberal: reformas para atrair o capital estrangeiro, fortalecimento da dolarização e retirada do Equador da OPEP. Correa, por sua vez, propôs aprofundar a "Revolução Cidadâ": integração latino-americana, impedimento das privatizações e proteção das empresas públicas, avanço dos programas sociais, economia a serviço do ser humano. A despeito da crise, Correa venceu no primeiro turno. Foi a primeira vez que isso ocorreu desde a redemocratização em 1979. Isso teria se devido ao fato de que "Correa tem conseguido, ainda que 
com grandes restrições estruturais, cumprir sua agenda política" (PEDROSO, 2010, p.27).

\section{Considerações finais}

O governo de Rafael Correa deflagrou um processo de transformação do país, centrado na busca do desenvolvimento com base em maior autonomia nacional, na ação do Estado na economia, na integração regional e na melhoria da distribuição de renda e das condições de vida da população. Mas, segundo vários analistas equatorianos, dentre eles Alberto Acosta ${ }^{37}$, o Equador ainda defronta-se com sérios problemas antigos e recentes, tais como:

- o ainda forte peso do capital estrangeiro no país ${ }^{38}$, que interfere no nível de autonomia nacional e implica em forte drenagem para o exterior de recursos gerados internamente;

- a dolarização da economia, que dificulta a realização de política econômica voltada para o desenvolvimento;

37 Conforme palestra ministrada a um grupo de pesquisadores brasileiros, na FLACSO do Equador, no dia 22.07.2010. Alberto Acosta, antigo professor de Economia da FLACSO do Equador, foi ministro de Rafael Correa, assumindo depois a presidência da Assembleia Nacional Constituinte, quando se desentendeu com o Presidente a propósito dos encaminhamentos da Constituinte, passando então a ser um dos críticos mais contundentes da nova administração.

38 "Algumas das empresas maiores estão fundindo-se ou vendendo-se a companhias estrangeiras” (SALTOS; VAZQUEZ, 2009, p.239). 
- a preponderância do modelo primário-exportador, que engendra vulnerabilidade externa na economia ${ }^{39}$;

- uma economia rentista com base no petróleo, que faz o comportamento da economia depender da renda gerada por um único produto;

- a forte concentração de riqueza ${ }^{40} e$ renda $a^{41}$, que dificulta o desenvolvimento do mercado interno e a promoção de um melhor nível de vida para a população.

39 O setor manufatureiro em 2009 não empregava mais que $14 \%$ da força de trabalho; enquanto isso, cerca de $3 / 4$ das exportações, em 2008-09, era representado por produtos primários (Ibid., p.64, 239, 274, 275). Pior ainda, com concentração das exportações para um único mercado: em 2008, cerca de $45 \%$ das exportações equatorianas destinava-se aos EUA (SALTOS; VÁZQUEZ, 2009, p.275).

40 Os 25 principais grupos econômicos do país controlavam em 2007 $25,58 \%$ do PIB equatoriano. No setor financeiro, a concentração era ainda maior: os cinco principais grupos financeiros detinham, em dezembro de 2008, 78,18\% dos ativos do sistema financeiro privado; o maior grupo, o Pichincha, detinha sozinho 33,6\%; o setor financeiro público participava com apenas $25 \%$ do conjunto do sistema financeiro (SALTOS; VÁZQUES, 2009, p.269, 295, 296, 297).

41 De acordo com o Informe de Desenvolvimento Humano de 1999, elaborado pelo PNUD, enquanto os $20 \%$ mais pobres da população recebiam apenas $2,5 \%$ da renda nacional, os $20 \%$ mais ricos auferiam $58,7 \%$ (Ibid., p.298-299). O índice de pobreza experimentou uma diminuição no governo Correa - de 37,60\% em dezembro de 2006 para 33,01 em junho de 2010 -, mas seguiu elevado (INEC, 03.03.2011). 


\section{Referências}

AYALA MORA, E. Resumen de História del Ecuador. 3.ed. Quito: Corporación Editora Nacional, 2008.

BANCO CENTRAL DO EQUADOR. Balance General Consolidado. 31.12.2010. Disponível em: <www.bce.fin.ec>. Acesso: 03.03.2011.

. Cifras económicas del Ecuador, vários números.

2011. Disponível em: <www.bce.fin.ec>. Acesso: 03.03.2011.

. Disponível em: <www.bce.fin.ec>. Acesso: 16.02.2011.

CARVALHO, C.E.; ALMEIDA, M.; WOCHLER, R.V.; BRAGA, C.; PEDROSO, C. A América Latina e a crise: impactos iniciais e primeiras reações. São Paulo: [s.n.], 2010.

CEPAL. Anuario Estadístico de América Latina y el Caribe. 2008.

COELHO, A. L. "As eleições equatorianas de 2006 e os desafios à governabilidade”. Observador On-Line, v. 1, n. 8, out. 2006, Rio de Janeiro: Observatório Político SulAmericano, IUPERJ/UCAM.

. "Os movimentos sociais equatorianos e bolivianos - atuações e implicações para a governabilidade”, 2008, Rio de Janeiro: Observatório Político Sul-Americano, IUPERJ/ UCAM. 
CORREA, R. Dolarización y desdolarización: más elementos para el debate. Comentários al dossier de Iconos. Iconos, Revista de Ciencias Socialres, Quito: Facultad Latinoamericana de Ciencias Sociales-Sede Acadêmica de Ecuador. n. 20, sep.2004.

. Ecuador: de Banana Republic a la no República. Bogotá: Debate, 2010.

DECLARACIÓN de la VII Cumbre del ALBA - TCP. Cochabamba, Bolívia, 17 out. 2009.

ECUADOR. Constitución del Ecuador, 2008, Asamblea Constituyente.

FLORES, F.P.; CUNHA FILHO, C.M.; COELHO, A.L. Mecanismos de democracia participativa: o que há de comum nas constituições da Bolívia, Equador e Venezuela. Observador On-Line, v. 4, no. 7, jul. 2009. Rio de Janeiro: Observatório Político Sul-Americano. IUPERJ/UCAM.

INEC. Datos preliminares Censo de Población y Vivienda 2010. Disponível em: <www.inec.gob.ec>. Acesso: 04.03.2011.

INEC. Pobreza por ingresos: resultados a junho 2010. Disponível em: <www.inec.gob.ec>. Acesso: 03.03.2011.

PALACIOS, F. C. El Ecuador de 2008: proceso constituyente y el nuevo orden político-administrativo. Papéis Legislativos, Rio de Janeiro: Observatório Político SulAmericano, IUPERJ/UCAM, v. 2, n.3, ago. 2008. 
PEDROSO, C. S. Conjuntura política do Equador: os significados da reeleição de Rafael Correa e os desafios à estabilidade democrática. São Paulo, 2010.

RECALDE, P. Elecciones presidenciales 2006: una aproximación a los actores del proceso. Iconos, Revista de Ciências Sociales, Quito: Facultad Latinoamericana de Ciências Sociales-Sede Acadêmica de Ecuador. no. 27, PP. 15-25, enero 2007.

SALTOS, N; VÁZQUEZ, L. Ecuador, su realidad. 17. ed. Edición actualizada. Quito: Fundación de Investigación y Promoción Social José Peralta, 2009. 